Association for Information Systems

AIS Electronic Library (AISeL)

\title{
Process digitalization in dental practices - status quo and directions for the German health care system
}

\author{
Karolin Bosch \\ Ostbayerische Technische Hochschule Amberg-Weiden \\ Linda Mosenthin \\ Ostbayerische Technische Hochschule Amberg-Weiden \\ Christian Schieder \\ Ostbayerische Technische Hochschule Amberg-Weiden
}

Follow this and additional works at: https://aisel.aisnet.org/wi2021

Bosch, Karolin; Mosenthin, Linda; and Schieder, Christian, "Process digitalization in dental practices status quo and directions for the German health care system" (2021). Wirtschaftsinformatik 2021 Proceedings. 14.

https://aisel.aisnet.org/wi2021/XStudent/Track03/14

This material is brought to you by the Wirtschaftsinformatik at AIS Electronic Library (AISeL). It has been accepted for inclusion in Wirtschaftsinformatik 2021 Proceedings by an authorized administrator of AIS Electronic Library (AISeL). For more information, please contact elibrary@aisnet.org. 


\title{
Process digitalization in dental practices - status quo and directions for the German health care system
}

\author{
Karolin Bosch ${ }^{1}$, Linda Mosenthin ${ }^{1}$ and Christian Schieder ${ }^{1}$ \\ ${ }^{1}$ Technical University of Applied Sciences Amberg-Weiden, Weiden Business School, \\ Weiden, Germany \\ \{k.bosch,1.mosenthin,c.schieder\}@oth-aw.com
}

\begin{abstract}
Process digitalization in health care systems can help to increase treatment quality and foster cost-efficiency at the same time. Several studies have already shown how digitalization can change and automate processes, but do not address the specific needs of dentists. This paper investigates the status quo and the possibilities of process digitalization for dental practices and their interfaces. Based on the assessment of 101 participants of an empirical study and semistructured interviews with four dentists and four professionals of statutory health insurance we provide insights into the current situation. The analysis reveals that most organizations are in an early stage of digital transformation but are actively working on enhancing the digitalization of their processes. To meet this need, our results deliver a detailed description of prevailing challenges and starting points for process digitalization and optimization in the field of dentistry.
\end{abstract}

Keywords: German healthcare system, dental practice, administrative processes, business process automation, process digitalization

\section{Introduction}

Healthcare systems today are struggling with a variety of different and growing challenges. Limited financial resources, an aging society, and increasing multimorbidity within the population are the limiting factors pressuring resource allocation. New and sophisticated technologies bring new possibilities but frequently put even more stress on financial resources due to their cost intensity. At the same time, medical care of the patient needs to be guaranteed at the highest possible standard [13]. Therefore, continuous improvement is necessary. To tackle the tension between efficiency and quality, the digitalization of health care processes has become increasingly important in recent years. With digital process management, it is easier to locate bottlenecks, redundancy, and inefficiency and to initiate countermeasures against them. As a prerequisite, all participants in the health care system need to be highly process-oriented. They need to know and analyze their processes to realize the right potential for optimization [4].

These challenges affect not only the health system in general but also all specialized areas such as dentistry. Dental health affects the whole human body and is therefore a vital part of holistic human medicine. Whereas several studies have already shown how 
digitalization can improve and automate processes, they do not specifically address dentists and their interfaces [5-10]. This paper investigates the status quo and the directions of process digitalization in dental practices and their interfaces in the German health care system. Therefore, dentists' and statutory health insurance employees' perception of the current state of process digitalization was examined using semistructured interviews. Furthermore, we conducted an online survey to understand patients' perceptions of actual processes and digitization in the field of dentistry. We aimed to gain the most comprehensive insight possible into the status quo of processes digitalization and to extract starting points for further process optimization.

The remainder of this paper is organized as follows: Section 2 lays out the theoretical background and section 3 describes the methodology of the research. The results are presented in section 4 and discussed in section 5 before we conclude the paper in section 6 indicating the limitations of our research and providing an outlook to future work.

\section{Theoretical Background}

Quality improvement in healthcare stands for improved patient health, better medical care, and targeted professional development. To achieve this, targeted interdisciplinary cooperation between all those involved, such as the health care professions, payers, and managers, is required. This cooperation requires precise knowledge of the processes and procedures in the healthcare system [3]. The term business process can be defined as a series of logically related tasks that are performed to achieve a defined result. The definition of processes in healthcare is the same, except that they achieve a specific clinical outcome. Healthcare processes can be divided into two different types. On the one hand, there are the organizational, administrative processes and on the other hand the medical treatment processes [4, 5]. Processes can map all work and behavioral steps of the various parties along with the treatment of a specific patient or along the entire value chain of the system. Attributes of processes, such as capacity, efficiency, and reliability, illustrate important performance dimensions of healthcare, such as lead time and patient safety. Finally, they have a significant influence on patient satisfaction, costs, and the quality of medical care [6].

By using the right technology, such as modeling systems, process management can be more effective. Technological process management supports the various possibilities of digitization. The optimal management of administrative processes with data-based workflows and the simultaneous use of the right software can advance the digital transformation [11].

The complexity of the German healthcare system is shaped by different actors, institutions, and levels. All organizations and their roles in health care concerning dentists are summarized in the chart below [12-17]. 


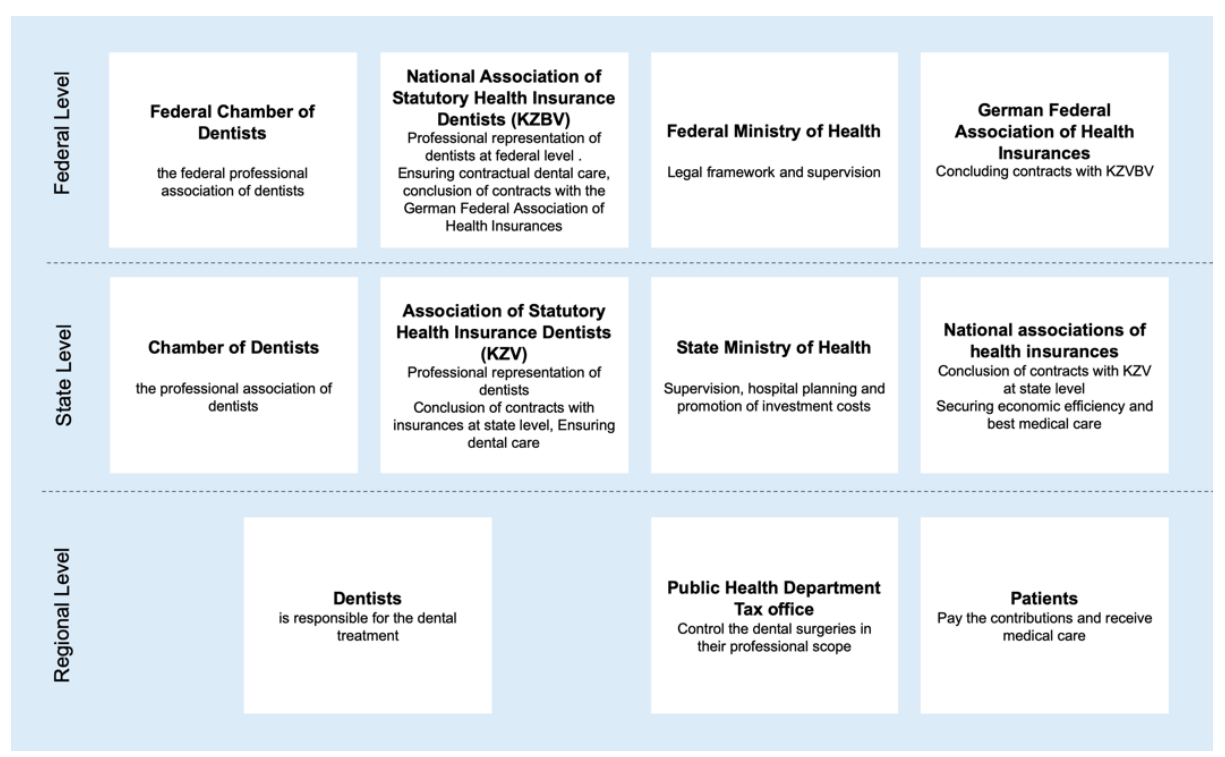

Figure 1. Different levels of the German healthcare system

The German Ministry of Health has recognized the need to digitize the system and has therefore drafted several laws for comprehensive reform. The basis for this is the telematics infrastructure (TI), which as digital platform networks all players in the statutory health insurance system. On this platform, all information can be securely exchanged across all sectors of the system. The connection to the TI is mandatory for all health care providers. For patients, participation is voluntary. Patients have sovereignty over their data and decide who receives what data and which applications they want to activate. In principle, the secure and digital exchange of treatment and medication data is intended to increase treatment safety and efficiency. Since the beginning of 2019, all dentists must be connected to the TI. The first implemented application is the online comparison of the master data of the insured persons. Other applications, such as the electronic medication plan, the standard case data management, and the electronic patient record (ePA) are currently under development $[18,19]$.

\section{Methodical Approach}

To obtain the most comprehensive picture possible of the status quo, a qualitative and quantitative approach was chosen. On the one hand, expert interviews were conducted with relevant actors in the healthcare system. On the other hand, an online survey was conducted. This approach is intended to examine the current situation from different perspectives. For a holistic view, the respective results are combined.

The conducted expert interviews were semi-structured and based on an interview guideline that was adapted to the specific expert groups. Each interview was scheduled 
for one hour and was held online via video or telephone. The goal of these interviews was to clearly define the administrative processes in dental practices and their interfaces as well as the possibilities of optimization and automation through digitalization. In order to obtain all the information required, the interview guide was set up accordingly. Priority was to understand the role and task of the interviewee and his or her organization and to capture all administrative processes in the organization and the interfaces to the dentists. In addition, personal wishes regarding work and process optimization, the current status of digitization, the possibilities and opportunities of digitization, and personal attitude to digitization were also to be surveyed [20-22].

A total of four participants (two women; two men; no miscellaneous) of a statutory health insurance company were interviewed, one participant working in the field of telematics and the other three in the dental domain. Four interviews (three women; one man; no miscellaneous) were conducted in the dental field. Three of the interviewees work as dentists, two of them have a leading position in a practice and are selfemployed, the fourth person is a dental administrative assistant.

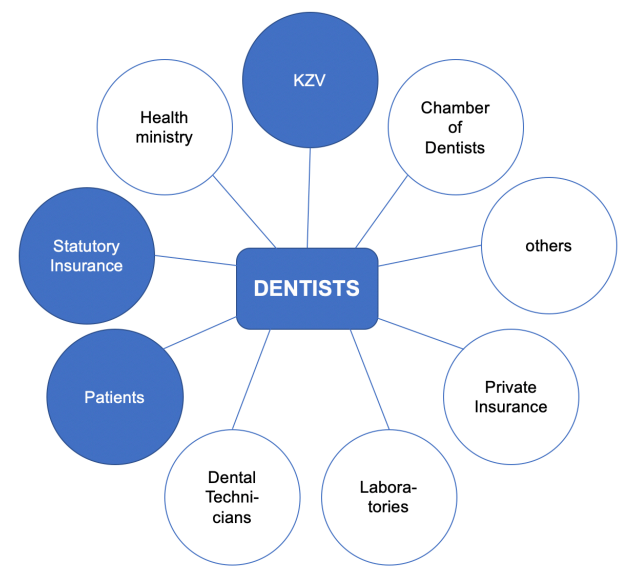

Figure 2. Possible and investigated interfaces to dentists (blue)

An online survey was carried out online without target groups to survey a representative cross-section of the society. Before the survey began, the participants had to agree to the respective consent and data processing declaration. First, sociographic data and the insurance status were queried. The survey aimed to find out the opinion of the population on digitization in everyday life in cooperation with dentists and insurance companies [23, 24]. A total of 101 persons ( 58 women; 43 men; no miscellaneous) aged over 18 years participated in the online survey. 


\section{$4 \quad$ Results}

In the following section, the results of the interviews and the survey are presented in detail one by one. All results were measured on the gradual ten-point response scale in Likert format.

\subsection{Interview with experts from a health insurance company}

First, a comprehensive analysis and evaluation of the results of the semi-structured interview with the health insurance company are presented. Due to the open questions that were asked during the entire interview, no significance and correlation between the individual results can be calculated. It was not relevant which gender or age the participants had, it was only about the professional experience and their field of application. On average, the interviewees have a work experience of 26.25 years. They feel that digitization is very helpful in their everyday lives (9.125 out of 10), although the current level of digitization in their field of work is only in the middle of the range (5.875 of 10). The desire and the existing potential to make the daily work more digital became clear from the results. Cooperation with all interfaces is rated as quite good ( 7.25 out of 10$)$, but there are still some areas where process optimization is necessary.

Table 1. Administrative processes

\begin{tabular}{lll}
\hline \multicolumn{1}{c}{ Processes } & $\begin{array}{c}\text { Current status of } \\
\text { digitalization }\end{array}$ \\
\hline 1. Performance audit & $\begin{array}{l}\text { Cor performance auditing, all billing } \\
\text { reports are sent to the health insurance } \\
\text { company via PDF. }\end{array}$ \\
\hline 2. Approval process & $\begin{array}{l}\text { In this process, there is an automatic mail } \\
\text { dispatch via ePost. }\end{array}$ \\
\hline 3. Settlement process & $\begin{array}{l}\text { The entire settlement process works on the } \\
\text { digital level as long as it is not interrupted } \\
\text { by errors. }\end{array}$ \\
\hline $\begin{array}{l}\text { 3.1 Process of } \\
\text { correction loop for }\end{array}$ & $\bigcirc$ & $\begin{array}{l}\text { Starting at the point where a review of the } \\
\text { process is necessary, the system switches } \\
\text { fettlements }\end{array}$ \\
\hline
\end{tabular}

The tasks of the health insurance company include the admission of dentists, invoicing, taking over remuneration negotiations, and answering questions relevant to the profession. Direct contacts with dentists are very rare and only take place when problems arise or wishes and innovations are to be discussed at a strategic level. On the administrative level, there is contact with the Association of Statutory Health Insurance Dentists (KZV). Digitalization has already progressed. For example, mails are scanned and automatically distributed as an eFile to the relevant departments. Between 1500 and 2000 applications are received daily by mail and are digitized. Invoicing is also already digital, as the software, checks the billing applications, and only conspicuous cases are forwarded to the clerks. Overall, less than $10 \%$ are classified as conspicuous 
and over $90 \%$ are processed directly by the system in digital form. The reports for the performance audits are sent to the health insurance company as PDF files and analyzed by them. The three administrative processes are shown in the table below.

Deficits of digitization. Despite optical character recognition (OCR), the allocation and appropriate distribution of incoming mails are relatively difficult. Here, the technology and the entire process should be more mature and advanced. The compatibility of the different organizations as well as technical systems of health insurance companies, dentists, and the KZV is not given and therefore there are many barriers. Besides, due to existing political barriers, cooperation with the KZV on a strategic level is often problematic. The data flow and all communication between the health insurance companies and the KZV are not transparent and therefore important information is sometimes lost. Currently, dentists and the KZV only pass on data that is helpful for the assessment to a limited extent. A lot of collected data is withheld because the KZV does not consider it necessary for the billing process of the insurance company. This means that the health insurance company often lacks information for a precise examination of the treatment provided.

Possibilities of digitization. In general, paperless collaboration and the automation of mass business would mean more time for customer care and thus increased customer satisfaction. Greater transparency through digitization means that fraud is less possible. A bonus app could also help to digitize the current analog bonus system to simplify the calculation of the subsidy for dental prostheses. In the future, admissions, assessment procedures, and court proceedings should have to be digitized. TI and ePA will increase efficiency and save costs. This means that once approved, patient data can be digitally transferred from doctor to doctor and from health insurance company to doctor. However, communication with patients will continue to take place by post. One of the risks of the electronic patient file is "dental stalking".

\subsection{Interview with dental practices}

In the following, the results of the interviews with dental practices are explained. For the evaluation of the results, the same conditions apply to the health insurance company. The average number of professional experiences in years is very high with a value of 19.5 years.

The interviewee finds digitization helpful in their everyday life (7.25 out of 10), the current status in their practice is slightly better than average (6.5 out of 10) and cooperation with all interfaces is also rated as above average ( 7.75 out of 10$)$.

The entire health care system, external laboratories, and also tax consultants are seen as interfaces. In total five different administrative processes are relevant in a dental practice. These processes are appointment management, accounting, material and quality management, and personnel administration. 
Table 2. Current status of the administrative processes in dental surgeries

\begin{tabular}{lll}
\hline Administrative processes & $\begin{array}{c}\text { Current } \\
\text { status of } \\
\text { digitalization }\end{array}$ & \multicolumn{1}{c}{ Examples } \\
\hline Appointment & & $\begin{array}{l}\text { A scheduling tool, where experience shows } \\
\text { that online implementation is difficult to } \\
\text { achieve. }\end{array}$ \\
\hline Accounting & & $\begin{array}{l}\text { An interface between the tax office and } \\
\text { finance office is needed, preferably digital, } \\
\text { to be able to act more flexibly. }\end{array}$ \\
\hline Material planning & $\begin{array}{l}\text { Online tools for material planning and } \\
\text { procurement would enable automated } \\
\text { ordering and would save time for all } \\
\text { employees. }\end{array}$ \\
\hline Quality management & $\begin{array}{l}\text { Online quality management and the } \\
\text { completion of the required documents could } \\
\text { be designed online and immediately checked } \\
\text { by the respective office. }\end{array}$ \\
\hline Personal administration & $\quad$ & $\begin{array}{l}\text { Time and vacation planning online for all } \\
\text { employees to have a simple and quickly } \\
\text { customizable overview. }\end{array}$ \\
\hline
\end{tabular}

Currently, there are great differences between individual practices, especially in the area of billing and licensing. Due to different levels of competence of the contact persons at the health insurance companies, but also within the practice, the contact to health insurance companies, insurances, and KZV is very different.

Many dentists have been converting their systems from paper to digital for some time now, resulting in performance, transmission, and control problems. There are software products such as DAMPSOFT or synMedico that are designed to help with digitization. However, these are not adapted to the individual needs of a single practice and are relatively expensive. Due to the high costs associated with the introduction of such software products, the decision is often made not to use such programs. Moreover, the transition to digitization also means that a large number of new and different problems will arise in practice. Therefore, a permanent restructuring of practice often requires an external consultant and the help of IT specialists. Thus, in addition to software costs, long-term support costs are also incurred. Also, the digitization of various processes is not conducive to achieving the desired results. This is the case, for example, when making appointments online. The correct coordination of appointments is not conducive from a business point of view, as it could lead to overbooking or idle time in the practices.

Deficits of digitalization. Digitization brings with it a high degree of trust, and the misuse of data poses a very great danger. In addition, the conversion and training effort is immense and only makes the current situation even more difficult. Technology providers have often digitized their customer service. This makes it difficult to find simple help and quick support for technical questions. The number of possible evaluations is increasing, which provides more transparency, but logically also 
increases control by interfaces such as health insurance companies, health authorities, and tax authorities. The compulsory participation in TI is perceived as uncomfortable by all dentists surveyed.

Possibilities of digitization. Digitization can facilitate the billing process with partners and patient data can be used in a simple and encrypted form for research purposes. TI has been very active in the field of data protection and is very securely established in this area. The step of patient education could be simplified by digital media. The software can be expanded to include role-based ticket and inbox systems so that the workflow can be completely digital.

\subsection{Online questionnaire with customers}

In addition to the interviews just mentioned, the results of the online survey were analyzed in detail (all results with $\mathrm{p}<.05$ are shown as statistically significant). In the first step, negatively coded items were undone. Within the measurements, sum values and necessary calculations were formed according to the corresponding specifications. In principle, it was not relevant for the conduct of the study whether female, male, or diverse persons participated. The age of the test persons was also irrelevant. Nevertheless, it can be stated that with the number of 58 women out of a total of 101 participants and 43 men, a broad spectrum of genders was reached and therefore all generated results are representative.

The average participant in the survey is 28.64 years old and insured by the AOK (42.6\%), and has no supplementary dental insurance. The participant goes to the dentist 1.6 times a year and finds the processes in the dental practice and the cooperation between health insurance and dental practice relatively simple. In addition, the average participant generally finds digitalization very important and uses it in everyday life.

A total of 26 health insurance companies were counted, of which 2 account for the majority with $60.4 \%$ (AOK: $42.6 \%$, Techniker Krankenkasse 17.8\%). Otherwise, a large number of small health insurance companies such as Barmer GEK, IKK, Allianz, DAK-Gesundheit, DaBeKa were mentioned.

Of all participants, 18 had private and 83 statutory insurance, which corresponds to a total of $82.2 \%$. It should be noted that in the case of privately insured persons, there is no need for cooperation between the practice and the health insurance company, as the latter must handle the billing itself. On average, there is a very small difference between the assessment of the simplicity of the procedures in the dental practice and the simplicity of these procedures in the cooperation with the health insurance companies in the case of privately and legally insured persons. The concerns expressed by the participants relate to cybersecurity, transparency, and cooperation. The following table shows all relevant correlations and their significance in terms of how customers perceive process optimization in dental practice.

There is a significant connection between the feeling of simplicity of the processes as a patient in the dental practice and the feeling of cooperation between health insurance companies and dentists $(\mathrm{r}(101)=.41 ; \mathrm{p}=.00)$. The general perception of the importance of digitization in everyday life also influences the perception of the sense 
of digitalization in dental practices $(\mathrm{r}(101)=.52 ; \mathrm{p}=.00)$. In addition, the general perception of digitization also influences the importance of cooperation between practices and insurance companies $(\mathrm{r}(101)=.32 ; \mathrm{p}=.001)$. The current degree of digitization in dental practices is perceived as well as the degree of cooperation between dentists and health insurance companies $(\mathrm{r}(101)=.48 ; \mathrm{p}=.00)$. Those who consider digitization in dental practices to be useful also find it useful in the cooperation between health insurance companies and practices $(\mathrm{r}(101)=.38 ; \mathrm{p}=.00)$. People who find digitization important also use it in everyday life $(r(101)=.49 ; \mathrm{p}=.00)$. The described and other significant findings are summarized in Table 3.

Table 3. Summary of the significant findings of the online survey

\begin{tabular}{l|l|cc}
\hline \multicolumn{1}{c|}{ Expression 1 } & \multicolumn{1}{c}{ Expression 2 } & \multicolumn{1}{c}{ (101) } \\
\hline $\begin{array}{l}\text { the simplicity of the processes as } \\
\text { a patient in the dental practice }\end{array}$ & $\begin{array}{l}\text { cooperation between health } \\
\text { insurance companies and dentists }\end{array}$ & $.41 * *$ \\
\hline $\begin{array}{l}\text { the general perception of the } \\
\text { importance of digitization in } \\
\text { everyday life }\end{array}$ & $\begin{array}{l}\text { the perception of the sense of } \\
\text { digitalization in dental practices }\end{array}$ & $.52 * *$ \\
\hline $\begin{array}{l}\text { the general perception of } \\
\text { digitization }\end{array}$ & $\begin{array}{l}\text { importance of cooperation between } \\
\text { practices and insurance companies }\end{array}$ & $.32 * *$ \\
\hline $\begin{array}{l}\text { the current degree of digitization } \\
\text { in dental practices }\end{array}$ & $\begin{array}{l}\text { degree of cooperation between } \\
\text { dentists and health insurance } \\
\text { companies }\end{array}$ & $.48^{* *}$ \\
\hline $\begin{array}{l}\text { the use of digitalization in dental } \\
\text { practices }\end{array}$ & $\begin{array}{l}\text { importance of the digitalization of } \\
\text { cooperation between dental } \\
\text { practices and insurance companies }\end{array}$ & $.38^{* *}$ \\
\hline $\begin{array}{l}\text { digitization in everyday life is } \\
\text { important }\end{array}$ & $\begin{array}{l}\text { use of digitization } \\
* \text { The correlation is significant at the } 0.05 \text { level (two-sided) } \\
* * \text { The correlation is significant at the } 0.01 \text { level (two-sided) }\end{array}$ & $.49 * *$ \\
\hline
\end{tabular}

\section{Discussion}

In the following, the presented results are discussed. Digitization in the healthcare sector is becoming increasingly relevant for all parties involved. This is shown by the results collected by health insurance companies, dentists, and patients. Each of these target groups considers the expansion of digitization and general process optimization in the dental sector to be target-oriented.

On the part of health insurance companies, this affects both the increased digitalization and automation of their internal processes and the cooperation with dentists. This is reflected in the various projects on which the health insurance companies are working. A large number of projects concern the general digitalization of internal approval and billing processes, but also the digitalization of the cooperation with the KZV, dentists, and the insured. The future automatic transmission of authorization from the health insurance company to the dentist carries the risk of jeopardizing the sovereignty of the patient. The authorization should always be 
transmitted via the patient to the dentist. An automated process should be designed accordingly.

There are different degrees of digitization among dentists. This is probably related to the size and entrepreneurial competence of the practices. In particular, the competence of the management to correctly interact with the interfaces to other companies and to recognize the limits and interfaces of processes is a key factor [25]. The digital transformation of processes is associated with major barriers and obstacles. First of all, additional efforts are required to convert to and familiarize themselves with the new technology. The introduction of standard software is only partially possible. The software must be adapted to the individual needs of a particular practice. There are also efforts to familiarize dental staff, dentists, and customers with digitization. For the dental staff, the changeover to digital solutions means that, in addition to familiarization, permanent training and troubleshooting is required. In addition, at the beginning of the changeover, double management of all files is necessary to avoid errors due to duplication of work. For these reasons, digitization is hardly economically viable and profitable for individual practices in the first step.

Despite the many disadvantages and the additional work involved in the changeover from analog to digital, long-term advantages in process optimization and workload reduction are possible. In the long term, dental practices hope to have more time for patient treatment and thus better care. Besides, the practices will benefit in the long term from easier customer information, documentation, and appointment management. They will thus support digitalization in the field of dentistry. Possible starting points for reducing the obstacles and efforts involved in digitization are the exchange of information between the various practices. By creating networks, practices can share knowledge and experience on how to switch over and use the software. In addition to knowledge, cloud-based process management enables them to work together on optimizing and digitizing their processes [11]. This exchange and standardization allow synergy effects to be leveraged.

From the collected results it is clear that there are general interfaces that should be digitized. These interfaces are more generally valid since they also affect other organizations. On the one hand, the digitization of the billing of dental practices, from bank data to tax consultants and tax offices, would make daily work easier. On the other hand, the digitization of the judiciary and its interfaces to dentists would also be a matter of the same importance. Another general wish is the development of video conference portals for larger conferences to enable a more personalized exchange.

Especially for dental practices, various approaches have emerged that could be designed and implemented. For example, the digitalization of the continuing education process, through information sheets and information platforms for patients, would simplify patient education and thus significantly simplify the daily routine of every dentist, since times are becoming shorter and education has already taken place in advance. A further example would be the possible extension of the existing software solutions by a role-based ticket and inbox system, to demonstrate a secure and simple administration of patients, files, and important tasks. An artificial intelligence, which queries all relevant factors, could be a solution for the future but would have to be 
further developed and include many factors. The technology thus offers a wide range of possibilities. It only needs to be adapted to the respective needs.

In general, all processes that affect the patient are more difficult to automate. The reason for this lies in the treatment plan, which is adapted to the patient. Each treatment plan spans different interfaces and organizations. Thus, each interface affects the flow of information and the timing component of the process. Patient behavior is difficult to predict and schedule into a process in a standardized way. One example of this is the dental information provided to the patient and its legally compliant digital documentation. In principle, all respondents to the online survey support digitization in the dental field and its interfaces.

The Ministry of Health has recognized the opportunities provided by digitization and is driving it forward with legislation. The aim is to force all players in the system to use a uniform digital procedure wherever possible. For example, all dentists must be connected to the TI. Some dental practices have already switched over to other digital technologies, on their own initiative.

Despite the efforts of the German government to create a uniform approach to digitization, there are many small-scale solutions and different approaches. The different perspectives of the various parties inevitably create barriers that make easy digitization difficult. These barriers would have to be disclosed to define a targeted approach to process digitization for all parties. This step is probably the most difficult step for targeted, successful, and patient-centered digitization of the entire dental sector across the different organizations.

In addition, there is generally little know-how in process management. Many potentials are seen in the development of necessary competencies and the correct application of digital process management. For targeted modeling and digitization of the process, a stakeholder analysis is an opportunity to unite the different intentions and perspectives of the interfaces. It is important to permanently include the voice of the patients. A patient-centric approach is essential for achieving this. The response to the TI will show whether it is already sufficiently user-centric or whether it needs to be developed further in this sense.

\section{Conclusion and Future Work}

This work is subject to some restrictions. For example, the healthcare system in Germany was examined with a focus on dentists. Therefore, no conclusions can be drawn about other healthcare systems. Likewise, the lack of patient insight into the processes in dental practices and their interfaces can lead to distortions. In addition, more interviews should be conducted for a more precise listing of all administrative processes. The number of interviews and the type of actors interviewed should be expanded.

This work can provide a basis for collecting more and deeper information about the individual parties involved and their processes in the future. It is the first step to explore to what extent processes in this sector can be digitized and which processes are most important in this context. It also serves to find out where there are gaps in digitization 
in the daily routine of dental practices and which daily tasks could be simplified through process optimization.

This thesis aimed to get a first impression of the processes and the possibilities for optimization and automation, as there is generally little research on this topic so far. For a specific process analysis, more intensive research is necessary. For this purpose, research should specialize in all interfaces and their processes (see figure 1). To get a detailed result, each organization involved in the system should be considered separately. Differentiation of the processes between public and private health insurance companies is also useful. This is where the statutory health insurance companies should have the most interfaces since the private health insurance companies only have contact with the patients.

The presented general and dental approaches can be concretized and investigated in further work. The field of dentistry, like many areas of daily life, is undergoing digital change. All affected organizations are trying to optimize and automate processes with the help of digitization. Often, however, they do this without consideration for each other and without involving the other parties involved. The results of the survey and interviews confirm this. They also show different starting points for future process optimization. These optimizations should be used comprehensively and purposefully in future work. In this way, the possibilities of digitalization can be used in the best possible way for dentistry. For an active and goal-oriented digital design of the healthcare system, the starting points shown should be taken up and deepened in future work. Digitization affects us all and should also have an impact on all areas of life. Therefore, dentistry should not stop it and should increasingly rely on the digitalization of analog procedures. 


\section{References}

1. Marsilio, M., Prenestini, A.: Making it happen: Challenges and transformations in health care processes, people management, and decision-making. Heal. Serv. Manag. Res. 33, 53-54 (2020). https://doi.org/10.1177/0951484820906314.

2. Porter, M.E., Lee, T.H.: The strategy that will fix health care. Harv. Bus. Rev. (2013).

3. McCullough, J., Economics, E.S.-J. of H., 2010, undefined: Monitoring technology and firm boundaries: Physician-hospital integration and technology utilization. Elsevier.

4. Buttigieg, S., Dey, P.K., Gauci, D.: Business process management in health care: current challenges and future prospects. Innov. Entrep. Heal. 1 (2016). https://doi.org/10.2147/ieh.s68183.

5. de Koning, H., Verver, J.P.S., van den Heuvel, J., Bisgaard, S., Does, R.J.M.M.: Lean six sigma in healthcare. J. Healthc. Qual. 28, 4-11 (2006). https://doi.org/10.1111/j.1945-1474.2006.tb00596.x.

6. Müller, R., Rogge-Solti, A.: BPMN for Healthcare Processes. (2011).

7. Mens, J., Ahlers, B., van Hattem, B., Ravesteyn, P.: Value-Based Healthcare Through a Standardised Process Management Model. ECMLG 2015 Proc. 8 (2015).

8. Rolón, E., Chavira, G., Orozco, J., Soto, J.P.: Towards a Framework for Evaluating Usability of Business Process Models with BPMN in Health Sector. Procedia Manuf. 3, 5603-5610 (2015). https://doi.org/10.1016/j.promfg.2015.07.748.

9. De Ramón Fernández, A., Ruiz Fernández, D., Sabuco García, Y.: Business Process Management for optimizing clinical processes: A systematic literature review. Health Informatics J. (2019). https://doi.org/10.1177/1460458219877092.

10. Gastaldi, L., Appio, F.P., Corso, M., Pistorio, A.: Managing the explorationexploitation paradox in healthcare: Three complementary paths to leverage on the digital transformation. Bus. Process Manag. J. 24, 1200-1234 (2018). https://doi.org/10.1108/BPMJ-04-2017-0092.

11. Lederer, M., Knapp, J., International, P.S.-2017 6th, 2017, undefined: The digital future has many names- - How business process management drives the digital transformation. ieeexplore.ieee.org.

12. Maier, C., Juschkat, T.: Digitization in the German Health Care System - An Analysis of the Status Quo Using the Example of the Dental Sector. Eur. J. Bus. Manag. Res. 5, (2020). https://doi.org/10.24018/ejbmr.2020.5.3.331.

13. Gesundheitswesen in Deutschland, https://vbw-zukunftsrat.de/Gesundheit-undMedizin/Analyse?box=56\&box_56=Gesundheitswesen-in-Deutschland, last accessed 2020/08/10.

14. Was macht ein angestellter Zahnarzt?, https://www.deutscher-zahnarztservice.de/blog/was-macht-ein-angestellter-zahnarzt, last accessed 2020/08/08.

15. KZBV - Kassenzahnärztliche Bundesvereinigung - Startseite, https://www.kzbv.de/, last accessed 2020/08/08.

16. Startseite: Bundeszahnärztekammer - Arbeitsgemeinschaft der Deutschen Zahnärztekammern e.V. (BZÄK), https://www.bzaek.de/, last accessed 2020/08/08.

17. Aufgaben und Organisation der GKV $\mid$ BMG, https://www.bundesgesundheitsministerium.de/themen/krankenversicherung/grundpri 
nzipien/aufgaben-und-organisation-der-gkv.html, last accessed 2020/08/10.

18. Telematikinfrastruktur, https://www.gematik.de/telematikinfrastruktur/, last accessed 2020/08/10.

19. E-Health - Digitalisierung im Gesundheitswesen,

https://www.bundesgesundheitsministerium.de/e-health-initiative.html, last accessed 2020/08/09.

20. Louise Barriball RGN Research Assistant, K.B., While RGN RHV Cert Ed, A.: Collecting data using a semi-structured interview: a discussion paper. (1994).

21. McIntosh, M.J., Morse, J.M.: Situating and constructing diversity in semi-structured interviews. Glob. Qual. Nurs. Res. 2, (2015).

https://doi.org/10.1177/2333393615597674.

22. Flick, U., von Kardorff, E., Steinke, I.: Wolff in Flick et a . 178-183 (2004).

23. Evans, J.R., Mathur, A.: The value of online surveys. Internet Res. 15, 195-219 (2005). https://doi.org/10.1108/10662240510590360.

24. Sue, V., Ritter, L.: Conducting Online Surveys. SAGE Publications, Inc. (2015). https://doi.org/10.4135/9781506335186.

25. Caputo, A., Fiorentino, R., Garzella, S.: From the boundaries of management to the management of boundaries: Business processes, capabilities and negotiations. Bus. Process Manag. J. 25, 391-413 (2019). https://doi.org/10.1108/BPMJ-11-2017-0334. 